\title{
Liver Cancer pTX TNM Finding v7
}

National Cancer Institute

\section{Source}

National Cancer Institute. Liver Cancer PTX TNM Finding v7. NCI Thesaurus. Code C90156.

Liver cancer in which the primary tumor cannot be assessed. (from AJCC 7th Ed.) 